\title{
Un manuscrito poético desconocido en la Biblioteca de la Hispanic Society of America
}

\author{
Manuel Ángel Candelas Colodrón \\ Universidad de Vigo
}

Título: Un manuscrito poético desconocido en la Biblioteca de la Hispanic Society of America.

Resumen: El artículo pretende describir un manuscrito poético singular, conservado sin catalogación en la Biblioteca de la Hispanic Society of America y desconocido hasta hace muy poco tiempo. Se trata de una colección muy variada de poemas entre los que destaca un conjunto de coplas musicadas, de naturaleza amorosa, y algunas composiciones satírico burlescas relativas a la situación política de finales del reinado de Carlos II y comienzos de la dinastía borbónica.

Palabras clave: Manuscrito poético, Poesía española del siglo XVII, Reinado de Carlos II, Cancionero musical, Pasquines burlescos.

Fecha de recepción: 17/2/2016.

Fecha de aceptación: 19/4/2016.
Title: An Unknown Poetic Manuscript in the Library of the Hispanic Society of America.

Abstract: The article tries to describe a singular poetic manuscript, kept uncatalogued in the Library of Hispanic Society of America, remained unknown to this date. It is a very varied collection of poems: among them stands out a group of sung love verses and some burlesque and satirical compositions about the political situation of Spain at the end of the kingdom of Carlos II and the beginning of the Bourbon dinasty.

Key words: Poetic Manuscript, 17th Spanish Poetry, Kingdom of Carlos II, Musical Songbook, Burlesques Leaflets.

Date of Receipt: 17/2/2016

Date of Approval: 19/4/2016.

En los archivos de la Biblioteca de la Hispanic Society of America se halla un cartapacio compuesto por pliegos de diferentes letras, al menos veinte, de distinta mano y de muy variada precisión caligráfica. Se trata de un vo- 
lumen sin catalogar y sin registrar, procedente al parecer de los llamados "Papeles de Altamira".

Geoffrey Parker, en la nota sobre las fuentes utilizadas para su biografía de Felipe II, cuenta cómo el imprescindible fondo documental del último conde de Altamira fue desperdigado en varios lotes tras el reparto de títulos nobiliarios entre sus hijos². Parecían reconocidas las ubicaciones de cuatro de esos lotes: 1) el Archivo Zabálburu, el banquero bilbaíno que, a instancias de Sancho Rayón, compró 522 carpetas de sus legajos; 2) la Biblioteque Publique et Universitaire de Ginebra, del bibliotecario del último conde, Paul Chapuys; 3) la British Library, a partir de la venta hecha por un cuñado del último conde, Frédéric Disdier; y 4) el Instituto Valencia de don Juan, creado por Guillermo de Osma, que fue capaz de reunir datos fundamentales sobre los aspectos centrales de la vida de Felipe II (Mateo Vázquez, el secretario Antonio Pérez, Juan de Austria).

Parker revela que Sancho Rayón se quedó con unos 3000 papeles de la colección y que éstos fueron vendidos al marqués de Jerez, quien, como es sabido, vendió a su vez buena parte de su biblioteca y de sus posesiones artísticas al millonario estadounidense Archer Milton Huntington para nutrir la Hispanic Society of America, que este último había fundado. Estos papeles constituyeron parte de la valiosa colección de la Biblioteca de la $H S A$ pero no fueron catalogados hasta el año 2012, gracias a una beca de la Andrew Mellon Foundation que permitió a Bethany Aram, Rachel Ball y al propio Geoffrey Parker hallar nueva documentación sobre los años de la vida de Felipe II.

Entre estos papeles, que, según Parker, llegaron al Conde de Altamira después de ser reunidos por el interés particular del conde duque de Olivares que se los había apropiado, se halla este manuscrito poético. El Catálogo de manuscritos poéticos de Rodríguez Moñino y Brey obviamente no lo registra, pero es interesante comprobar la afinidad de este volumen con algunos otros que sí fueron catalogados por Moñino/Brey de

1 Este trabajo sería imposible sin la extraordinaria generosidad de John O’Neill, curator de la Biblioteca de la Hispanic Society of America, quien dejó en mis manos este manuscrito para su estudio: vaya esta nota como dedicatoria personal y como profundo agradecimiento a su amable disposición.

2 Geoffrey Parker, El rey imprudente. La biografía esencial de Felipe II, Barcelona, Planeta, 2015, pp. 513-515. 
esa misma biblioteca de la $H S A$. No es extrańo, dada la materia de sátira política que contiene: en particular poemillas o pasquines relativos a los acontecimientos históricos del convulso final del reinado de Carlos II. La afinidad mayor se da con los manuscritos XCV y CXV del catálogo Rodríguez Moñino-Mariño Brey, que contienen copias de las composiciones "Faltó el pan en la plaza y al instante” (25), “¿Dónde está aquella vaina de Almirante?” (26) y “¿Oropesa sentarse? ¡Qué locura!” (48), que satirizan los sucesos acaecidos por la carestía del pan el 28 de abril de 1699, conocidos en buena parte de la historiografía de la época como el Motín de los Gatos ${ }^{3}$. En el manuscrito XCV aparecen también "¿Quién rige estos dominios?" (6) de la misma materia y "El curso transparente” (60), unas interesantes coplas que este manuscrito presenta en dos versiones: la 62 y la 66, esta última dedicada a una tal María Varela.

Las coincidencias de composiciones con otros manuscritos catalogados por Rodríguez Mońino-Marińo Brey son más infrecuentes, pero merecen resaltarse los poemas "Rey inconstante" (80 de esta colección), que se halla en el manuscrito XXXIII (205); “¡Oh miserable España” (número 19), en el LXXI (1); "En comunes frases Menga” (número 42), en el LXXXI (116, atribuido a Alonso de Olmedo); "Amor chocolatero" (número 66), en el XXXIII; o "La azucena es bella y fina” (número 78), en el manuscrito CLXXXII (87, asignado a Diego de Nájera).

Los textos de estas tres últimas composiciones, así como el de "El curso transparente", pertenecen a conocidas canciones de la época: son transcripciones de coplas destinadas al canto, cuyos testimonios podemos encontrar en algunos cancioneros musicales de la época. No son los únicos: al menos es posible consignar "Bella Amarilis Divina” (22); "Esto no tiene remedio" (42), que procede muy probablemente de Las grandes tonadas del Retiro, el entremés de Gil López Armesto; "Milagro, Belinda, fueras" (45), “Qué dulcemente aprisiona” (60), "De Daliso ofendida” (63), "Si la gloria de adorar" (64) o "Alado cisne de nieve" (72). Junto a los citados más arriba, suman un total de once poemas que deben ser considerados transcripciones de canciones, aunque es muy posible que aquellos que se presentan en forma de coplas con estribillo obedezcan a idéntica naturaleza. En ese caso, el número podría ascender a unas quince composiciones,

3 Véase sobre este particular Teófanes Egido, “El motín madrileño de 1699”, Investigaciones históricas, 2 (1980), pp. 253-294. 
incluido "Después de haber permitido" (7), que aparece como Villancico para noche de Reyes.

De noventa y cuatro composiciones que pueden contabilizarse en este volumen $^{4}$, más de la mitad son de carácter amoroso, de tamaño breve y con una decidida elocución media, con ligeras inclinaciones humildes. Dentro de este apartado se pueden inserir estas composiciones musicales. Abunda entre todas ellas la estrofa octosilábica (quintillas, décimas y coplas, con estribillos de canciones probablemente conocidas) y la estructura del romance, con no muchos versos. Los poemas, de declaraciones sencillas amorosas, parecen más billetes ingeniosos, con silogismos sobre la naturaleza confusa del locutor amante, que severas reflexiones sobre la condición melancólica del poeta. La métrica empleada, de arte menor, reduce la voluntad de una poesía severa o ambiciosa. La presentación de algunos de estos poemas, de desalińada caligrafía, parece resultado de una espontánea copia, sin afán de permanencia, de textos para memorizar o conservar durante un tiempo muy limitado; no parecen destinados estos textos a una preservación formal: más bien a la mera transcripción ocasional con fines circunstanciales inmediatos.

Sobresale la inclusión de una breve relación de títulos que bien pudieran haber sido proyectos de pequeño cancionero (que consigno con el número 65) o la repetición de tres poemas $(66,67$ y 68) dedicados a una tal María Varela (Maria Barela en la transcripción), aunque no escritos, por "el señor licenciado don Juan de Rojas y Yaguirre". No faltan, en general, las referencias a una naturaleza domesticada con postizas insinuaciones pastoriles (Amarilis y Belindas aparecen en algunas composiciones: 22 y 45), ni tampoco las composiciones limítrofes con la poesía más jocosa o decorosamente erótica, en la que aparecen nombradas mujeres de clase baja ("Son tus mudanzas, Gileta", 57; "Ha dado en ser fulanilla", 59; "En Málaga vi a Rufina”, 73) sin el obsceno léxico de la jácara burlesca.

El anonimato o la ausencia de indicación de autoría es total, a excepción del romance "Ya archiduquistar lográis" (77), dedicado a la defensa del rey Felipe V contra los malcontentos, en el que se especifica que son "Coplas que saca a la luz Felipe Rem, Poeta de Esquivias": la aclaración

4 Otorgamos número de catálogo a una breve lista de poemas y damos números diferentes a las dos versiones del poema "El curso transparente": eso explica el número total de 96 del catálogo. 
tampoco determina la autoría y, en cualquier caso, posee los indicios de una seudonimia ingeniosa que oculta más que revela al autor de los versos.

Aparte de estas composiciones de naturaleza festiva, en la que no falta el acompañamiento musical, destacan en esta colección, por su número, los seis poemas $(46,47,48,49,82,83)$ dedicados a la muerte de la reina María Luisa de Borbón o de Orleans ${ }^{5}$. Algunos de ellos parecen seguir determinaciones particulares de certámenes, como el soneto "Murió de España la Reyna amada” (46), que se presenta como acróstico, pero se ajusta a la regla de comenzar todos los versos por $M$ y terminar por — a, letra que aparece suprimida. O como el otro soneto, "De su lyra el son dulce armonioso" (49), que hace figurar como acróstico el nombre de la Reina, DONAMARIALUISA, transcrito en la hoja además en sentido apaisado.

Esta misma agudeza poética aparece en otros lugares, como en el papel titulado La gran comedia de la torre de Babel y confusa Babilonia que se representa en Madrid, reducida toda en personas: "La majestad cautiva-El Rey" (17). Compuesto muy probablemente sobre el año 1698, se trata de una suma de títulos de comedias famosas en la época, referidas con sentido crítico a distintas personalidades de la vida política del momento, y que debió de circular con profusión a juzgar por el número de testimonios aún conservados ${ }^{6}$. O el poema “. en boca yo tengo .” (41), con este juego tipográfico (de resultados conceptistas) de sustituir la palabra punto por el signo ortográfico.

5 Sobre estas composiciones a la muerte de la reina, puede verse el exhaustivo y completo trabajo de Inmaculada Osuna, "La poesía fúnebre en honor de María Luisa de Borbón (1689): formas y contextos editoriales", Criticón, 119 (2013), pp. 85-98, ceñido a la ingente producción impresa.

6 En el manuscrito 3612, "Miscel-lània històrica i literària", de la Biblioteca de Catalunya, de comienzos del siglo XVIII, aparece este poema satírico, ff. 7-8. (Eulàlia Duran, dir., Repertori de manuscripts catalans (1620-1714). Volum I. Barcelona: Biblioteca de Catalunya, Barcelona, 2006, p. 465). En la misma biblioteca se halla copia manuscrita en el libro F. Bon. 5475, ff. 168-168v. En las observaciones del catálogo online se detalla: "La gran comedia de la torre de Babel es troba també BC, Ms 3612 [3], i no descrit, a F. Bon. 7804 (també enregistrat a la sèrie de ms. amb la signatura 2310), f. 5-6, amb l'addició “año de 1698”. En la BNE de Madrid también se puede leer copia en el mss/13939, "Papeles varios curiosos t. 6", h. 143$143 \mathrm{v}$. Son ejemplos de una vasta difusión, ya que los libros de historia del siglo XIX incluyen el texto como muestra de la sátira política de este período concreto. 
El humor no falta en líneas generales en estas limitadas audacias expresivas, quizá lastrado por el sentido satírico de la gran parte de las composiciones. Con esta contrastada inclinación, las quintillas, probablemente de José de Montoro, "Bravo assumpto oigan sin miedo" (16), dedicadas Al pedo que soltó el Duque de Osuna estando jugando a las damas con D. Manuel de Silva en la pieza obscura en Palacio, pueden dar la clave del tono gozoso de la labor compiladora del componedor del volumen manuscrito ${ }^{7}$.

Pero el interés primordial de estas composiciones se halla en la preponderancia de la musa censora, destinada a distintos episodios, anécdotas y personajes de la vida política española de fin de dinastía. Composiciones a la Chamberga (12), el nombre vulgar con el que se conocía, por su atuendo, el cuerpo del ejército de Carlos II; un largo romance a Guillermo III (5), rey de Escocia, que concede la corona al archiduque Carlos III, en la pugna por la sucesión española; súplicas poéticas a la llegada del rey Felipe $\mathrm{V}$, que constituyen una de las composiciones más conocidas de la época, "Ven, adorado Felipe" (34), que lleva el subtítulo de Gritos de Madrid y que aparece regogida en numerosos testimonios ${ }^{8}$; o el romance "Famoso Felipe Quinto", puesto en boca de Castilla la Vieja, prosopopeya que, con la excusa de dar la bienvenida al nuevo rey, sirve para hacer memorial de quejas sobre el estado ruinoso del país.

Entre estos poemas de sátira política se halla la difundida composición "En Córdoba hay terrible ventolera" (19), enunciada por la viuda de Carlos II, Mariana de Neoburgo. En ella la reina debate sobre qué ciudad española puede elegir para conseguir el señorío, tal y como deja por escrito su marido en el testamento. El poema constituye un tópico

7 Alain Bégue, “"Degeneración» y "prosaísmo» de la escritura poética de finales del siglo XVII y principios del XVIII: análisis de dos nociones heredadas”, Criticón, 103-104 (2008), pp. 21-38, comenta este poema como de Pérez de Montoro: "Puede tratarse de una referencia explícita a un suceso como en las quintillas " $i B r a v o$ asunto oigan sin miedo!», inspiradas por un "acontecimiento" palatino que Pérez de Montoro relata de manera jocosa y explícita en los primeros versos" (p. 27).

8 Véase al respecto María José Rodríguez Sánchez de León, "La Guerra de Sucesión española en los pliegos poéticos de la Biblioteca Universitaria de Salamanca, Cuadernos dieciochescos, 1 (2000), pp. 185-208. En el manuscrito titulado Varias y ingeniosas poesías se incluye este poema sobre la llegada de Felipe V al trono español (p. 206). 
en la construcción histórica del personaje: aparece siempre asociado a su biografía? . De otra índole, con propósito patriótico, es el texto de la composición encomiástica que fue leída en la acción de gracias a la Virgen de Atocha por recuperar la plaza de Landau en 1703 (perdida un ańo antes a manos de las tropas del Archiduque Carlos). El texto aparece modificado con posterioridad para dejarlo como encomio a la victoria sobre las tropas portuguesas (ayudadas por Inglaterra). La Guerra de Sucesión europea desde el punto de vista del nuevo rey Felipe $\mathrm{V}$ es el telón de fondo de la composición poética.

Los nombres propios que aparecen citados en estos poemas son célebres protagonistas de la vida política del país a finales del siglo XVII y comienzos del XVIII, normalmente asociados a distintas facciones del poder. La falta de heredero de Carlos II hace que, durante los últimos años de su reinado, los partidarios de la perpetuación de la dinastía austríaca se enfrenten a la llegada de la dinastía borbónica. En esas dos grandes líneas de confluencias políticas se sitúan los distintos personajes de estas sátiras. El trabajo de Teófanes Egido sobre los sucesos de la primavera de 1699 me exime de mayor explicitación al respecto. Pero por los versos de este conjunto de poemas satíricos asoman Francisco Ronquillo, el corregidor madrileño implicado en el citado motín, considerado un golpe de estado encubierto de la facción borbónica contra los austríacos, el defenestrado Juan Tomás Enríquez de Cabrera, Almirante Mayor de Castilla (1691-1705) o el Conde de Oropesa, Manuel Joaquín Álvarez de Toledo (1664-1707), Presidente del Consejo de Castilla, valido de Carlos II, partidario de los Austrias y depuesto de forma contundente tras los disturbios mencionados.

El Cardenal Portocarrero (1635-1709), Luis Fernández Portocarrero, que ocupó cargos eminentes y actuó de casi regente entre los últimos días de Carlos II y Felipe V, es protagonista de un breve pasquín: "Los remedios de la francesa / los remedió Mazzarino / y ahora los de España / remediará este Pollino", fechado además el 29 de marzo de 1699. No faltan las menciones a ministros o cargos importantes de esa época, como los de la décima "Fray Redondo el confesor" (93), donde aparecen los

9 En el manuscrito 3612, "Miscel-lània històrica i literària", de la Biblioteca de Catalunya, ya citado, aparece una copia de este poema con el título "La reyna viuda de Carlos II”, f. 64v. Véase Eulàlia Duran, op. cit., p. 466. 
propios Cardenal Portocarrero o Juan Tomás, el Almirante, así como la condesa de Berlips, dama muy conocida de la corte final de Carlos II y sospechosa de ser la promotora de los hechizos que hicieron acreedor al rey de su legendario sobrenombre.

En otras composiciones aparecen escenas cortesanas, como la décima, "Unidos en hermandad", que recoge la conversación entre los condes de Monterrey y de Frigiliana, ministros habituales en los últimos gobiernos de Carlos II y en los primeros del nuevo monarca borbónico. La muerte repentina, no exenta de sospechas, el 19 de enero de 1699, de Pedro Núñez de Prado, Presidente del Consejo de Indias y Gobernador General de Hacienda, da lugar al soneto 25 , con un título bien definitivo, "Pedro Núñez ha muerto de repente", recogido en otros testimonios manuscritos.

Se trata, pues, de un volumen muy valioso para dos cuestiones básicas: para enriquecer el elenco de las composiciones circunstanciales con protagonistas del mundo cortesano alrededor de los últimos años del reinado de Carlos II y para dar a conocer los textos de algunas composiciones musicales famosas en esa época. Las composiciones sobre personajes de la corte se centran con notable insistencia en tres momentos: la muerte de la reina María Luisa de Borbón en 1689, a la que se dedican seis composiciones; el denominado Motín de los Gatos, un levantamiento popular repentino que en realidad presentó trazas de golpe de estado aristocrático para eliminar a la facción proaustríaca en 1699; y las victorias del rey Felipe $\mathrm{V}$ durante los años primeros de su reinado. La cronología, pues, no se remonta mucho más atrás del año 1680 y no sobrepasa en general la primera década del siglo XVIII. Ofrecen datos interesantes sobre ciertas posiciones políticas, muy críticas con la deriva de algunos ministros o presidentes de instituciones de la monarquía de los Austrias. Estas composiciones se enmarcan en la sobresaliente producción satírica de la época, comprobable con cierta facilidad con la consulta de la documentación histórica del momento. Las composiciones musicales, por su parte, corroboran la extensión de su fortuna, pero también permiten adivinar la existencia de otros poemas más desconocidos. Hemos podido ver las coincidencias con otros textos y partituras aparecidos en cancioneros musicales polifónicos del siglo XVII, pero es muy posible que algunas de las composiciones de este manuscrito permitan aumentar, sin duda, el repertorio. 


\section{RELACIÓN DE COMPOSICIONES}

1. "Un doctor donde la muerte". 20 quintillas. Poema satírico.

2. "Carlos Segundo, en quien vemos". A nuestro Catholico Monarca. Romance. 192 versos $^{10}$.

3. “Señor Ronquillo, no dirá por qué". Al soneto que responde la ida del Almirante. Soneto.

4. “Seo Juan Thomas, no me dirá por qué". A la ida del Almirante. Soneto. Sátira política.

5. "Por el santo rey Guillermo". Respuesta al parabién que el caballero irlandés da al Sr. Archiduque Carlos Tercero de hacerse coronado Rey de España por un hidalgo escocés desde la imprenta de Bizarron. Romance. 216 versos.

6. “¿Quién rige estos dominios? No lo sé”. Soneto.

7. "Después de haber permitido". Estribillo: "Toquen, toquen a marchar". Villancico para noche de Reyes. Coplas.

8. "Rey inconstante". España desasosegada y incapaz de remedio. Pasquín.

9. “Ya se cerró este figón”. La covachuela. 6 versos romanceados. Tamaño billete.

10. "Oh miserable España”. Romance. 48 versos.

11. "Noble nació la santa". Santa Rosalía.

12. "Pues ser Juan Anardo". Letrilla a la Chamberga. Tonadilla.

13. "De un pueblo que ha empezado ya a mandar". Soneto.

14. "Unidos en hermandad". Estando juntos hablando en Nuestra Señora de la Soledad el Conde de Monterrey y el de Frigiliana. Décima.

15. "Los remedios de la francesa"["los remedió Mazzarino / y ahora los de España / remediará este Pollino"]. Este Pasquín se puso en las puertas del Sr. Cardenal Portocarrero viernes 29 de marzo de 1699.

16. "Bravo assumpto oigan sin miedo". Al pedo que soltó el Duque de Osuna estando jugando a las damas con D. Manuel de Silva en la pieza obscura en Palacio. Quintillas. 110 versos.

17. "La majestad cautiva-el Rey". La gran comedia de la torre de Babel

10 En el manuscrito 18210 de la BNE, titulado Papeles varios del reinado de Carlos II, se halla una versión de este largo romance: ff. 150-161v. 
y confusa Babilonia que se representa en Madrid, redunda toda en personas. Un dramatis personae. Sátira política.

18. "Famoso Felipe Quinto". Castilla la Vieja, por estar impedida y enferma y no poder y en persona a dar la bienvenida a su Rey el señor Felipe Quinto, se la da por escrito en este Romance. Dice la causa de sus trabajos.

19. "En Córdoba hay terrible ventolera". Soliloquio de la Viuda, Reyna de España.

20. [Diferentes romanzes] “¡Ay, adorado peligro".

21. “¡oh tú, que mis deseos". Romance.

22. "Bella Amarilis divina". Romance ${ }^{11}$.

23. "Mal haya yo, señorita”. Romance.

24. "Entre cuántas donosuras". Romance.

25. "Pedro Núñez ha muerto de repente". Soneto".

26. "Faltó el pan en la plaza y al instante".

27. “¿Dónde está aquella vaina de Almirante”. Soneto.

28. "Lot, que en Sodoma vivió" [/ la libertó del castigo / porque era de Dios amigo / el tiempo que allí vivió]. Se añade una Respuesta de Madrid.

29. "No extrañareis, virgen bella". Acción de Gracias que hace en María en Nuestra Señora de Atocha por la restauración de la plaza de Landau. 17034. Romance.

30. "Belígero rumor muy resonante". En ocasión de haber visto un soneto rumboso con extravagantes equivocos. Dedicado al muy ilustre señor don Joseph Manrique de Lara, mi capitán de la Guarda del Excmo Sr. Marqués de Astorga y Virrey deste Reino de Nápoles. Antecede una décima de presentación: "Conságroos afectuoso", y un subtítulo:

11 Se trata de unas coplas también incluidas en el valioso Manuscrito Guerra, ms. 265 (ff. 40v-41), custodiado en la Biblioteca Xeral de la Universidad de Santiago de Compostela, cuyo nombre remite al del copista José Miguel de Guerra y Villegas, de la Capilla Real de la corte de Carlos II, que contiene composiciones musicales. "Buelue, Amarilis, Diuina" se titula en el manuscrito compostelano, datado alrededor de 1680, según indican Pablo Rodríguez y Álvaro Torrente, Journal of the Royal Musical Association, vol. 123, 2 (1998), pp. 147-189, quienes lo han catalogado y estudiado.

12 Mercedes Etreros, La sátira política en el siglo XVII, Madrid, Fundación Universitaria Española, 1983, pp. 259 y 301. 
Habla con el soneto, por ignorarse su autor deste soneto ${ }^{13}$.

31. Otra del mismo sujeto y para el mismo don Antonio, pidiéndole la plaza de lugarteniente por la gracia de tierra y de la mar. Décima.

32. Al Sr. Antonio de Guzmán, pretendiendo el sujeto autor la vigía de las torres de Calabria. Décima. [Están colocados al revés en el volumen]

33. "Un Rey, que en forma de Reyna”. Romance. 176 versos.

34. "Ven, adorado Felipe". Gritos de Madrid al Rey. 11 coplas con este estribillo. 1710 figura en el reverso.

35. "Elegía la plaza lo adornado hermoso". Soneto.

36. "Y de mi amor la atención". Décima.

37. "Yo adoro y callo porque". Décima.

38. "El respeto de mi amor". Décima.

39. "A la puerta del decoro". Verso libre alirado.

40. "Solís, el de Salamanca". Romance. 148 versos. A dos columnas ${ }^{14}$.

41. “. en boca yo tengo .". En defensa de los sacerdotes a quienes un lego o hombre de capa y espada trata de repartirles el punto de Theología escolástica tronzando en su idea. El poema coloca un punto en lugar de la palabra punto.

42. "Esto no tiene remedio". Baile de las tonadas del Retiro".

43. "En comunes frases, Menga". Romance. $32 \operatorname{versos}^{16}$.

13 El marqués de Astorga, Antonio Pedro Sancho Dávila y Osorio, fue virrey de Nápoles entre 1672 y 1675 . En Luis de Salazar, Historia genealógica de la casa de Lara, Madrid, Imprenta Real, II, 1697, p. 704, se menciona a este capitán ya fallecido por entonces: "Joseph Manrique de Lara, Cavallero de la Orden de Calatrava, Capitán de la Guarda del Virrey de Nápoles, Marqués de Astorga. El rey D. Carlos II, le hizo merced del hábito de Calatrava en 21 de enero de 1673 y se le despachó título dél en Madrid a 27 de abril de aquel ańo. Apartáronle del servicio del Rey sus achaques y falleció en Madrid".

14 José de Solís y Valderrábano (Salamanca, 1643-1713), virrey de Cerdeña, Presidente del Consejo de Indias.

15 Puede referirse al entremés de Gil López de Armesto y Castro, Las tonadas grandes del Retiro, pero no hallo las coincidencias. Se publicaron en 1674, en Madrid, por Roque Rico de Miranda.

16 De Alonso de Olmedo, según se describe en la Bibliografía de la literatura hispánica de José Simón Díaz. Del año 1688 es uno de los cancioneros donde figura, con la variante tenga por Menga (BNE Ms. 4049, fols. 454-456); y de 1712 data otro, con el mismo verso y con el título "A una Dama. Pintura" (BNE Ms. 3916, fols. 225r-226r). 
44. "Si adoro a Matilde". Estribillo: "Pues que adoro a Matilde". 5 coplas.

45. "Milagro, Belinda, fueras". Romance. 16 versos ${ }^{17}$.

46. "Murió de España la Reyna amada". Soneto acróstico a la muerte de la Reyna Nuestra Señora Doña María Luisa de Borbón.

47. "Vulgo de flores mirando". A la temprana muerte de la Reyna Nuestra Señora. Décima.

48. "Felice logra su suerte". Otra.

49. "De su lyra el son dulce armonioso". Soneto acróstico a la muerte de la Reyna Nuestra Señora María Luisa.

50. "Oropesa, sentarse qué locura”. Soneto.

51. "Has visto ya tus tretas, Oropesa". Otro.

52. "Mis puros obsequios". Romance. 36 versos.

53. "Aquí rendimientos míos". Romance. 28 versos.

54. “Ay de aquel mío desvelo”. Romance. 40 versos.

55. “Аy, adorado peligro". Romance. 20 versos.

56. “¡Oh tú, de los tormentos”. Romance. 40 versos.

57. "Son tus mudanzas, Gileta”. Por Perogrullo letra nueva. Estribillo: "Dime para qué / buscas falsedades en la buena ley". Coplas.

58. “¡Ay del que finó”. Otra. Coplas.

59. "Ha dado en ser fulanilla". Otra. Romance. 32 versos.

60. “¿Qué dulcemente aprisiona!”. Otro. Estribillo: "Qué dulcemente / siente el amor lo que siente". 5 Coplas ${ }^{18}$.

17 Puede tratarse de la composición de Lope de Vega, musicada por Manuel de Larrea, conocido como Padre Larrea, que, en ocasiones, aparece como "Milagro, Zelinda, fueras”. En Mariano Lambea, Nuevo Incipit de Poesía Española Musicada, Biblioteca Virtual Cervantes, p. 165, se catalogan varias composiciones con este título. En $\mathrm{La}$ música y la poesía en Cancioneros Polifónicos del siglo XVII. Libro de tonos humanos (1655-1656), Barcelona, CSIC, 2003, Mariano Lambea y Lola Josa comentan las coplas (pp. 41-42), reproducen el texto (p. 74) y transcriben la partitura (pp. 253255). En el Cancionero musical de Lope de Vega de Miquel Querol Gavaldá (Barcelona, CSIC, 1986) se indica la existencia de este texto musicado.

18 Mariano Lambea y Lola Josa, La música y la poesía en cancioneros polifónicos del siglo XVII. Volumen III. Cancionero Poético-Musical Hispánico de Lisboa. Volumen I, Madrid, Sociedad Española de Musicología, 2004, pp. 90-91 y 291-296, catalogan y editan una versión de esta composición musical anónima (con facsímil) como perteneciente al Cancionero Poético-Musical Hispanico de Lisboa. La titulan a partir del 
61. "Gemid, ruiseñor". Otra. 7 coplas.

62. "El curso transparente". 6 liras. Estribillo: "Peces, fieras, aves / sentid mis males"19.

63. "De Daliso ofendida”. 6 coplas. Estribillo: "A las peñas, las penas"20.

64. "Si la gloria de adorar". Estribillo: "No puede Amor / hacer mi duda mayor". Coplas ${ }^{21}$.

65. Listas de primeros versos en forma de borradores. [Algunos de ellos son de los que aparecen transcritos: "Ay, adorado peligro", "En tus mudanzas, Gileta" o "A las peñas, las penas".

66. "Amor chocolatero". Para Doña María Barela, que Dios guarde muchos años ${ }^{22}$.

67. "El curso transparente". Coplas. Estribillo: "Peces, fieras, aves". Para la señora doña María. El señor Licenciado don Juan de Rojas y Yaguirre.

68. "Pues sabe el alba ser". 7 estrofas. Para mi Barela. A Doña María, su bumilde criado.

69. "Dormido gentilísimo". Romance. 64 versos.

70. "Lo joven he ignorado". Romance. 20 versos.

71. "Suspende el arco y la flecha". Romance. 20 versos.

72. "Alado cisne de nieve". Romance. 16 versos $^{23}$.

estribillo, “¡Qué dulcemente siente!”. También indican en esa edición las variantes de otra versión en el ms. 3747 de la BNE.

19 De Agustín Salazar y Torres, musicado por Juan Hidalgo. El poema cuenta con numerosas versiones: doce al menos consignan Pablo Rodríguez y Álvaro Torrente, op. cit., p. 184, al catalogar el que figura en el cancionero del manuscrito Guerra compostelano (ff. 82v-83). Este texto se repite más abajo, en la composición 67 , dedicada a María Varela.

20 También se halla en el citado Manuscrito Guerra, ms. 265 (ff. 23v-24), en Pablo Rodríguez y Álvaro Torrente, op. cit., p. 178.

21 También se halla en el citado Manuscrito Guerra, ms. 265 (ff. 54v-55). Véanse Pablo Rodríguez y Álvaro Torrente, ibidem, p. 181.

22 Se trata, al parecer, de unas coplas musicadas que aparecen en otros manuscritos de la Biblioteca de la Hispanic Society, catalogados por Rodríguez Moñino y Brey Mariño, y en el manuscrito Gayangos Barbieri, descrito por Carmelo Caballero, "El manuscrito Gayangos-Barbieri", Revista de Musicología, XII, 1 (1989), pp. 199268.

23 Son coplas de Diego de Nájera y Cegrí, musicadas por Juan de Navas, según Pablo Rodríguez y Álvaro Torrente, op. cit., p. 185, ya que figuran en el manuscrito Gue- 
73. "En Málaga vi a Rufina”. Romance. 24 versos.

74. "Tímidos moradores del orbe". Romance. 40 versos.

75. "De groseras política juzgo". Cuartetas romanceadas. 32 versos.

76. “¡Oh, soberano joven!”. Romance. 24 versos.

77. "Ya archiduquistar lográis". Nuestro Monarca Felipe Quinto contra los malcontentos. Coplas que saca a la luz Don Felipe Rem, Poeta de Esquivias. Romance. 64 versos.

78. "Parabienes de fortuna”. Décimas a la suerte que tocó a un caballero mereciendo en ella a la Duquesa de Ursache. 4 décimas.

79. "La azucena es bella y fina". Letra de la azucena. Estribillo: "Luego es copia la más parecida / de la hermosura que hoy busca el amor". 8 coplas $^{24}$.

80. "Virgen de la Soledad". Romance. 48 versos.

81. "De la camarera un paje". Romance. 40 versos.

82. "Ya Clotos ha segado rigurosa". Octavas a la muerte de la Reyna Nuestra Señora María Luisa de Borbón.

83. "Se apagó en débil sombra luz robusta". A la muerte de la Reyna Nuestra Señora. [figura una numeración en la parte superior derecha, como procedente de otro conjunto de pliegos manuscritos: lleva el 340].

84. "Así de mi torpe mano". Enviando este soneto a un amigo. [Tiene que ver con el anterior: figura al reverso y el número en la parte superior izquierda es el 341].

85. "De una taberna a la esquina". Romance.

86. "Ah, del país que es allende". Romance. 228 versos. [Tiene una paginación particular: comienza en el 602 y termina en el 611, como si procediera de otro manuscrito. Concluye el poema con los versos: "Veinte y siete de febrero, / Villanueva de Carxana, / mil setecientos y cinco / y a Dios que nos dé su gracia”].

87. “¿Quién llama allá? ¿Quién el fuerte?”. [Incompleto: se interrumpe en el v. 46, en la página con el reclamo Ansi triste].

rra compostelano (ff. 92v-93). Están catalogadas en al menos cuatro testimonios. Véase, por ejemplo, Rita Goldberg, Tonos a lo divino y a lo humano, Madrid, Tamesis Books, 1981, p. 162.

24 Son coplas atribuidas a Diego de Nájera y Cegrí, con alguna variante: "La azucena es bella y linda". Véase Rita Goldberg, ibidem. 
88. "El haber hoy tantos malos" [Se lee f. 640 en la página superior derecha: parece ser el final de otro poema]. 46 versos.

89. "Ni aunque tú seas profeta". Romance.

90. "Más valgo yo que el Pirú". Romance. 72 versos.

91. "Ya había el grande hijo de Macrobio". Romance. 68 versos.

92. "Aquestes papeles tiernos". Décima.

93. "Fray Redondo el confesor". Décima ${ }^{25}$.

94. "Quien es noble en sí atesora". Estribillo: "Si donde hay amor hay celos, / donde hay nobleza también". Coplas.

95. "Qué pretendes hacer, señor Perico". Soneto ${ }^{26}$.

96. "La cándida paloma”. Romance. 16 versos.

25 En la hoja 84 del volumen manuscrito Carlos II, Ministerios de su reinado (ms. 18212 de la BNE), se reproduce este poema con el título Soneto. A los del Gobierno. También en Mercedes Etreros, op. cit., p. 322.

26 En Mercedes Etreros, op. cit., p. 228: 18. "Soneto al portugués. ("Que pretendes haçer señor Perico / con la liga que as echo con yngleses"): fol. 348v". 
Manuel Ángel Candelas Colodrón, Un manuscrito poético desconocido en la Biblioteca de la Hispanic...

ApÉndice. Ilustraciones

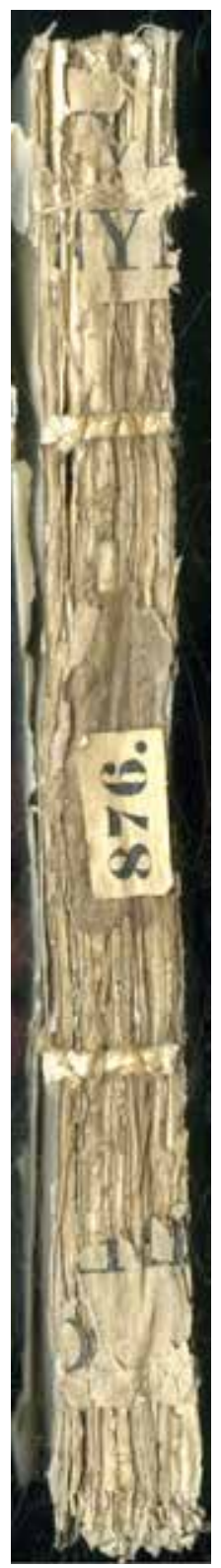

Fig. 1. Lomo del volumen de pliegos poéticos. 
Manuel Ángel Candelas Colodrón, Un manuscrito poético desconocido en la Biblioteca de la Hispanic...

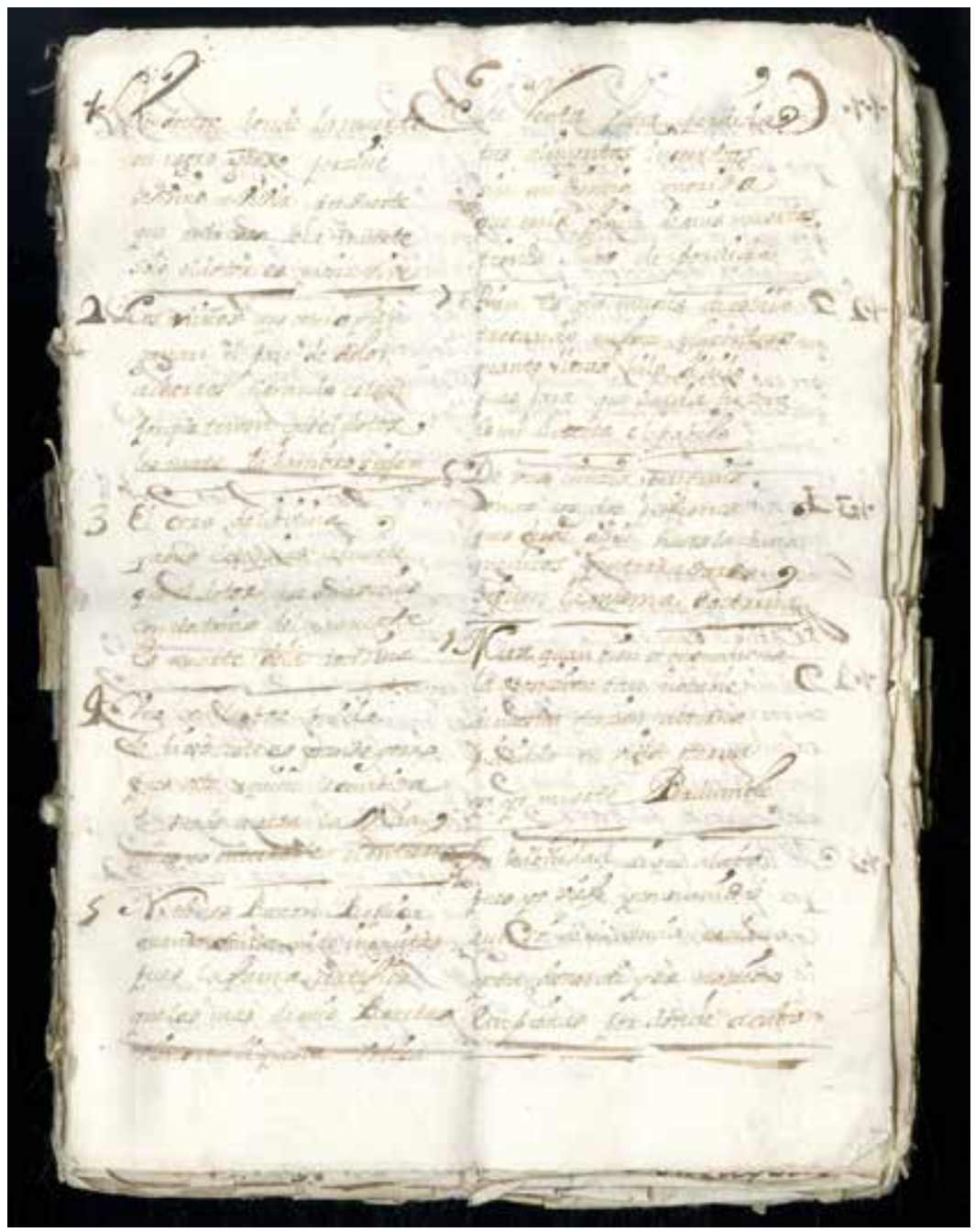

Fig. 2. Primera página. "Un doctor donde la muerte". 
Manuel Ángel Candelas Colodrón, Un manuscrito poético desconocido en la Biblioteca de la Hispanic...

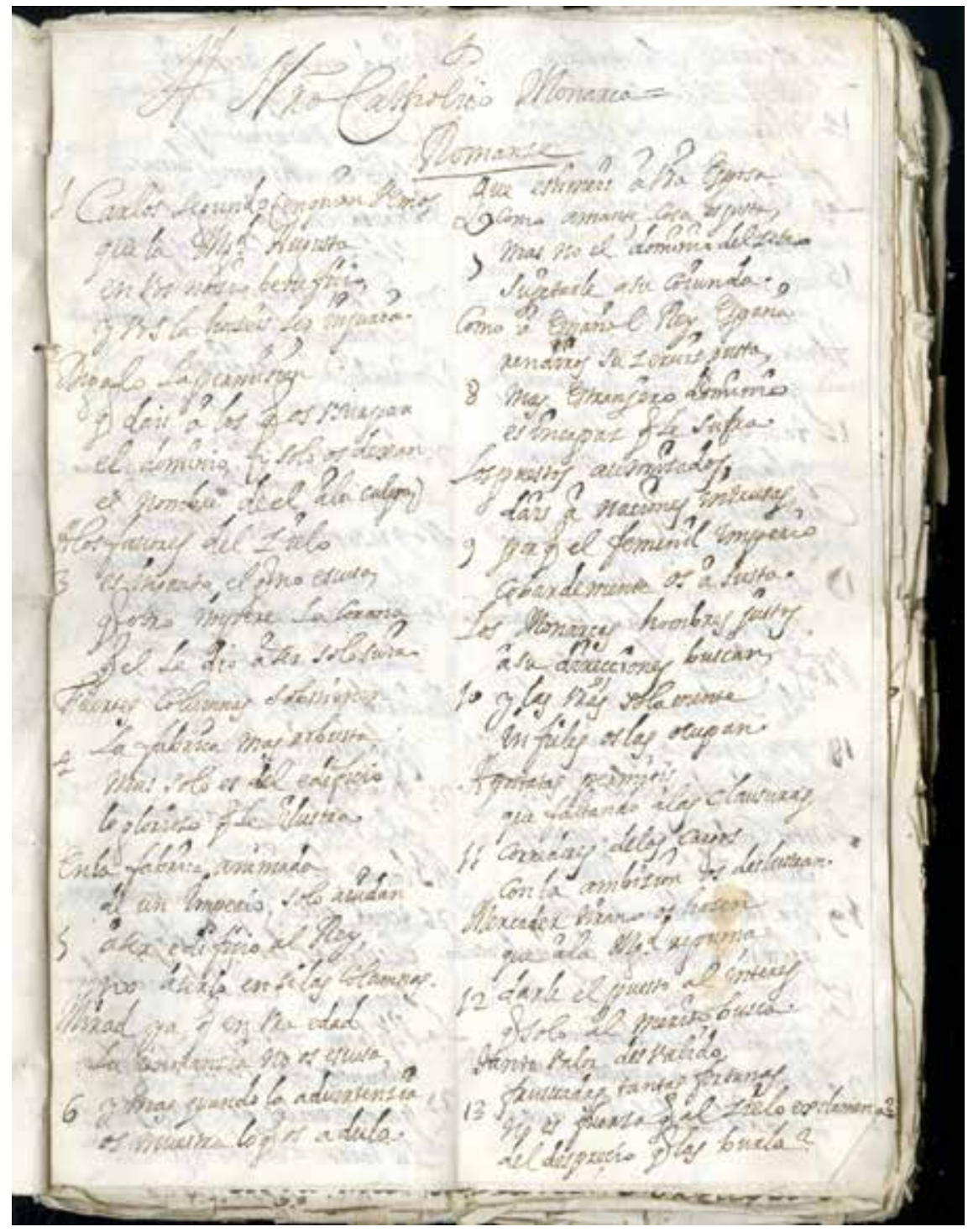

Fig. 3. A Nuestro Catholico Monarca. "Carlos Segundo, en quien vemos". 
Manuel Ángel Candelas Colodrón, Un manuscrito poético desconocido en la Biblioteca de la Hispanic...

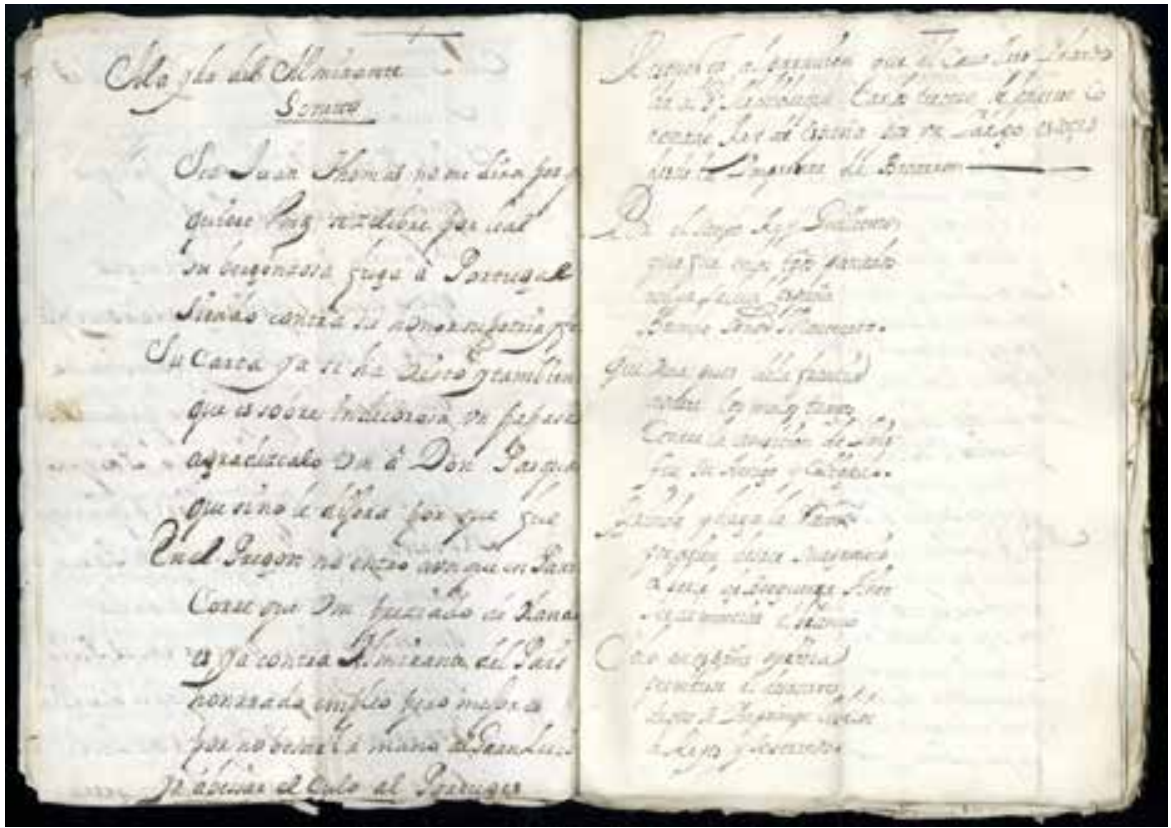

Fig. 4. Página de la derecha: A la ida del Almirante. "Seó Juan Thomas, no me dirá por qué". Página de la izquierda: Respuesta al parabién que el caballero irlandés da al Sr. Archiduque Carlos Tercero de haberse coronado Rey de España por un hidalgo escocés desde la imprenta de Bizarron. "Por el santo Rey Guillermo". 
Manuel Ángel Candelas Colodrón, Un manuscrito poético desconocido en la Biblioteca de la Hispanic...
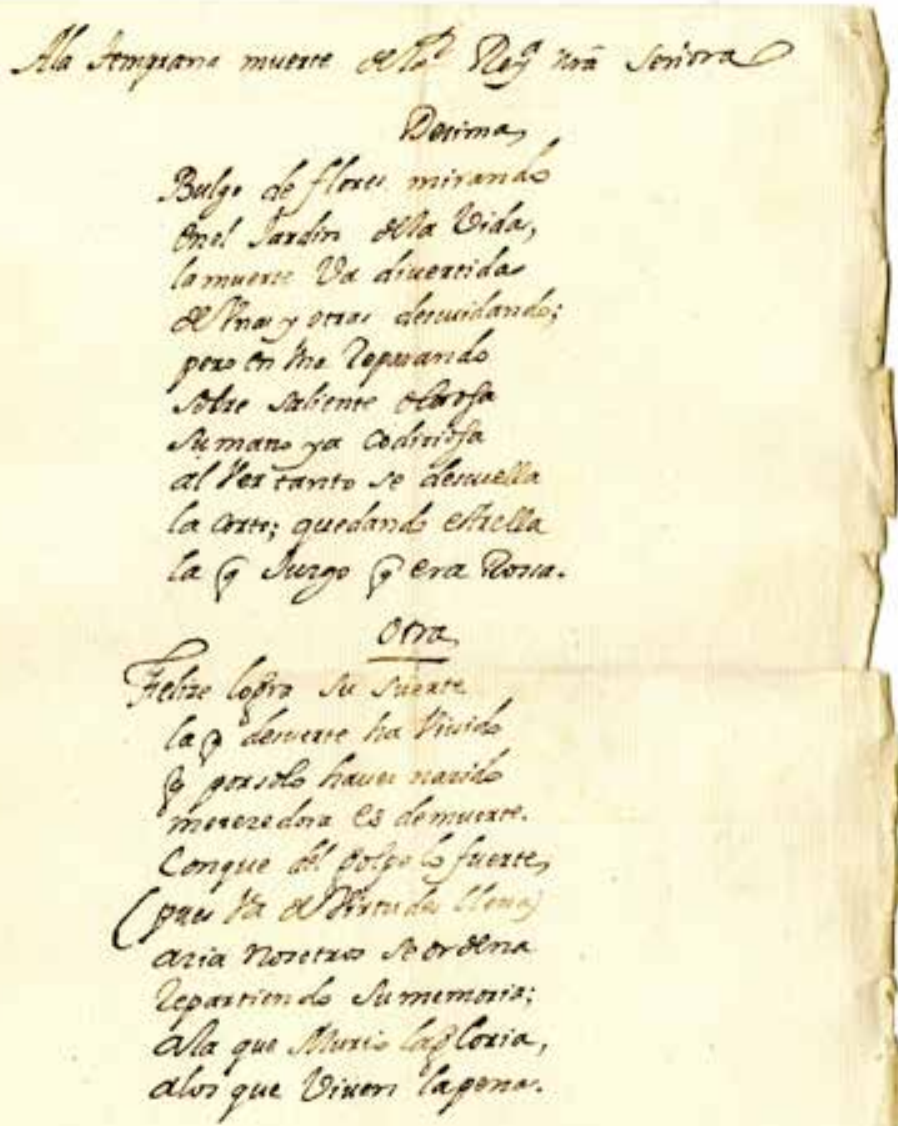

aise lobia die veext

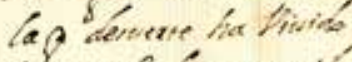

(6) parits have wawide

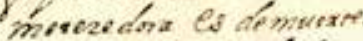

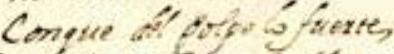

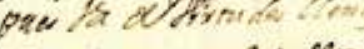

aria noetuo sorden

Reparstiondo camemats;

ala gue Aluxis Léloxia,

alor que biven Hepose

Fig. 5. A la temprana muerte de la Reyna Nuestra Señora. "Vulgo de flores mirando" y "Felize logra su suerte". 
Manuel Ángel Candelas Colodrón, Un manuscrito poético desconocido en la Biblioteca de la Hispanic...

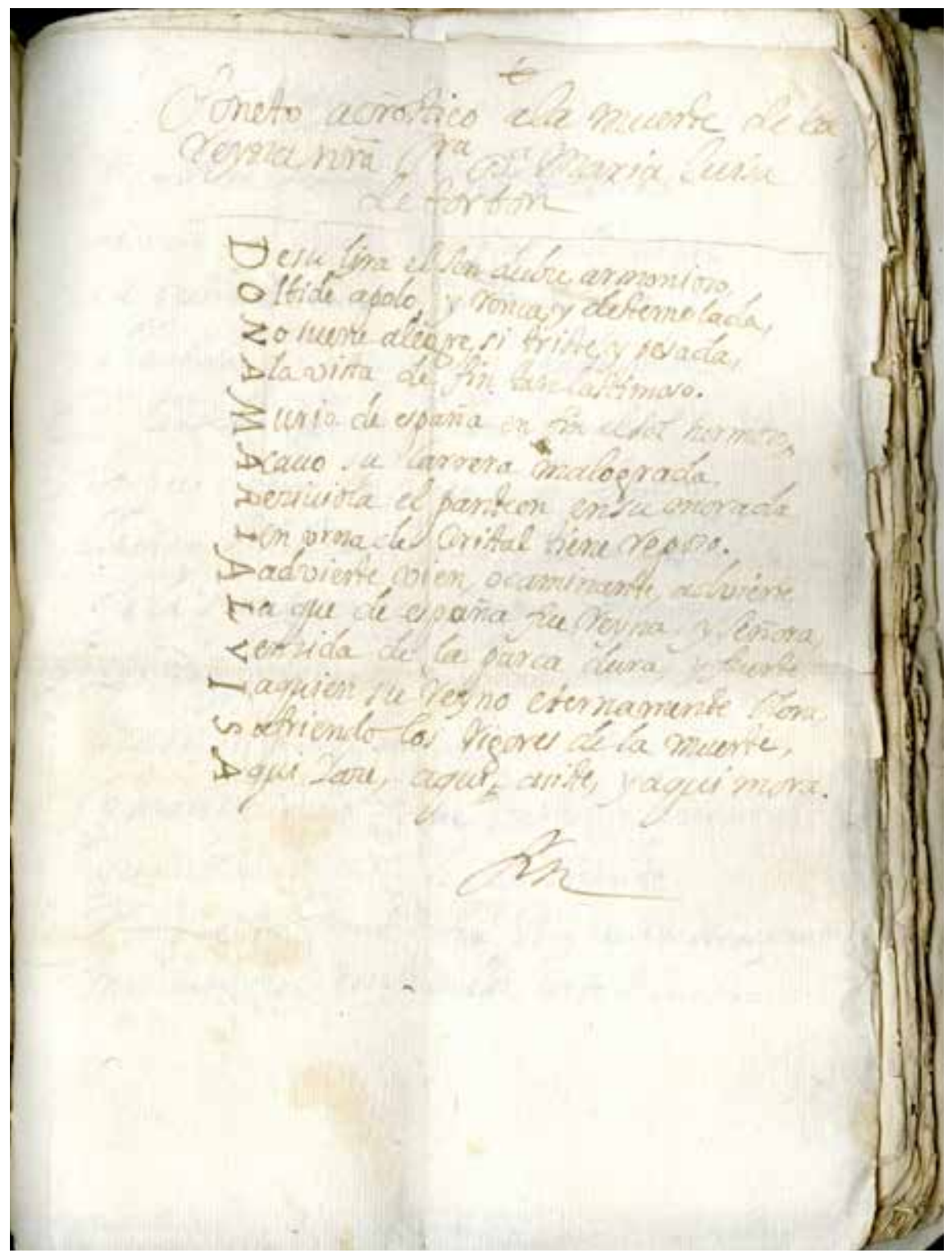

Fig. 6. Soneto acróstico a la muerte de la Reina Nuestra Señora Doña María Luisa de Borbón. "De su lyra el son dulce armonioso". 
Manuel Ángel Candelas Colodrón, Un manuscrito poético desconocido en la Biblioteca de la Hispanic...

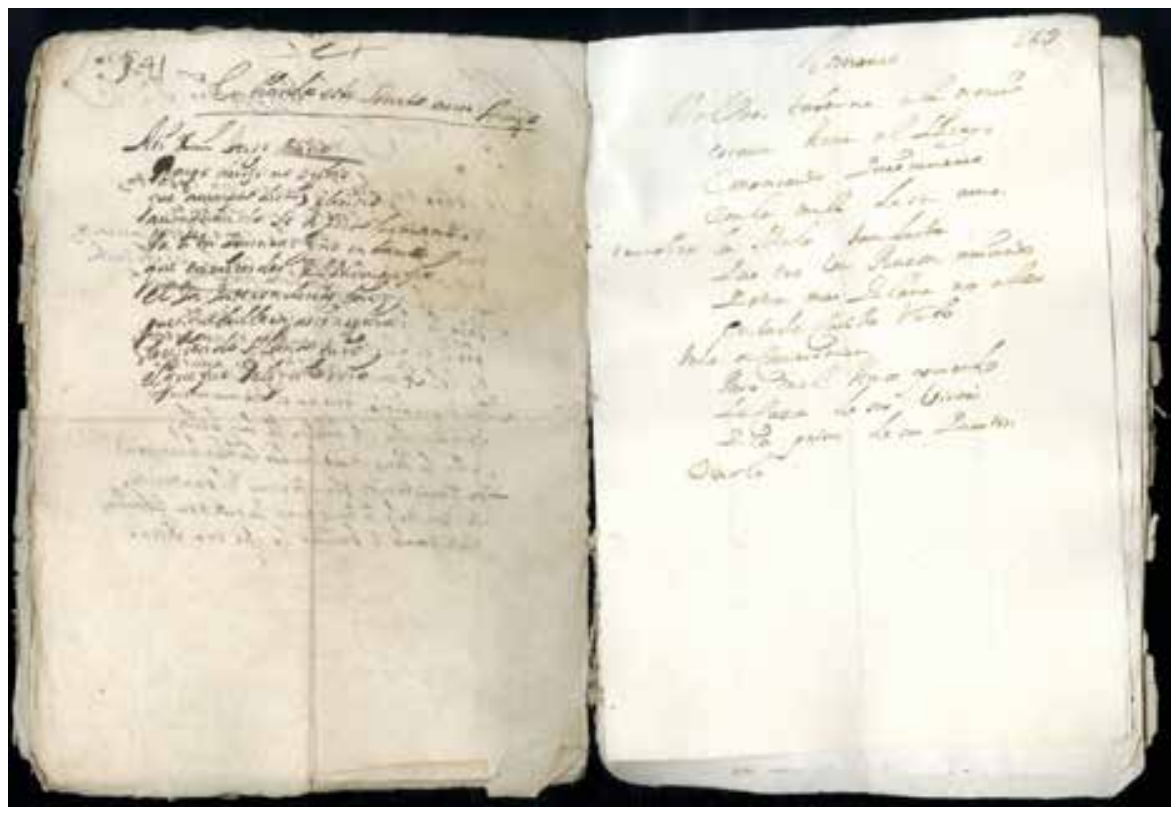

Fig. 7. Enviando este soneto a un amigo. "Así de mi torpe mano" [El soneto en cuestión se halla en el recto de esa hoja, por lo que se deduce que debió de ser cosida en el volumen al revés]. Romance. "De una taberna a la esquina". 
Manuel Ángel Candelas Colodrón, Un manuscrito poético desconocido en la Biblioteca de la Hispanic...

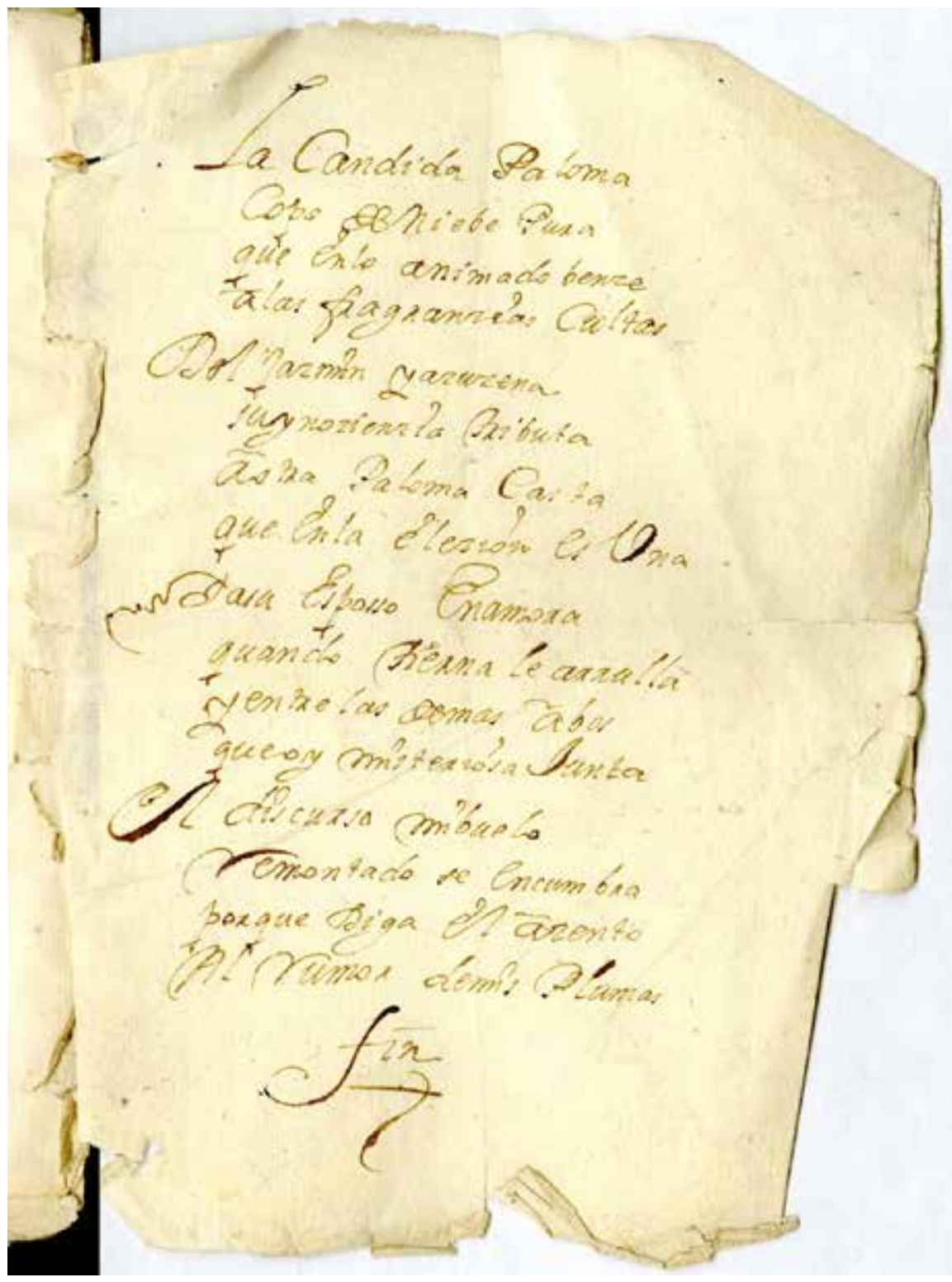

Fig. 8. Última página. "La cándida paloma”. 